\title{
A Utilização dos Materiais no Design e a Competitividade da Indústria Moveleira da Região Metropolitana de Curitiba: um estudo de caso
}

\author{
Joselena de Almeida Teixeira, Ms.C \\ Bacharel em Desenho Industrial pela UFPR, Especialista em Marketing pela FAE-CDE, Mestre em Engenharia de Produção pela UFSC. Professora \\ do Departamento de Desenho Industrial do CEFET-PR. \\ Av. Sete de setembro, 3845/214, Centro, Curitiba - PR, Brasil, CEP: 80250-210. E-mail: begu@netpar.com.br \\ Gesinaldo Ataíde Cândido, Ms.C \\ Professor Assistente do DAC-UFPB. Membro do IGTI(Núcleo de Pesquisa em Cestão, Inovação e Tecnologia de Informação) do PPCEP-UFSC. \\ Áreas de interesse em pesquisa: Política de Cestão para Pequenas e Médias Empresas(PME's), Processo de Formaçāo de Redes \\ Interorganizacionais entre PME's, Políticas de Desenvolvimento Regional e Competitividade Local \\ Rua Almirante Lamego, , 1436/104, Centro, Florianópolis-SC, CEP: 88015-601.E-mail: gcandido@eps.ufsc.br
}

Aline França de Abreu, Ph.D

Professora Adjunta do Departamento de Engenharia de Produção e Sistemas da UFSC e do Programa de Pós-Graduação em Engenharia de Produção da UFSC. Coordenadora de Núcleo de Pesquisa, ligado às áreas de Gestão, Inovação, e Tecnologia de Informação(IGTI).

Endereço: Rua João Pio Duarte Silva, 602, Bloco C/Ap. 302, Córrego Grande, Florianópolis-SC, CEP: 88037-001. E-mail: aline@eps.ufsc.br

O trabalho faz uma análise da utilização dos domínios e estratégias do Design e a sua relação com a competitividade do segmento moveleiro da Região Metropolitana de Curitiba em função da utilização dos materiais na criação, desenvolvimento e implementação do Design. A operacionalização da pesquisa se realizou mediante um estudo de caso, tendo como suporte teórico as variáveis: Design, materiais e competitividade. Para estabelecer um padrão de relacionamento entre as variáveis foram levantados os fatores de sucesso da competitividade da referida empresa e analisados à luz dos padrões de concorrência praticados na indústria de móveis. Para conjectura de explicação do relacionamento entre competitividade e as outras duas variáveis, os dados obtidos na entrevista foram, na seqüência, expostos aos modelos: estratégias genéricas de Porter (1986) e estratégias do Design (1993). O resultado desta exposição nos possibilitou inferir que a empresa busca vantagem competitiva por meio da diferenciação, no primeiro modelo citado. E, no segundo caso, há uma predominância na utilização do conceito aperfeiçoado.

Palavras-chaves: Design; materiais; competitividade

The work makes an analysis of the utilization of Design's domains and strategies and its relationship with the competitiveness level of the furniture segment from the Metropolitan Region of Curitiba concerning the utilization of materials in the Design's creation, development and implementation. The research realization was supported by a case study. The work was mostly based on the theoretical support of the following variables: Design, materials and competitiveness. To set relationship standard among the variables, were raised the factors of the competitiveness success of enterprise. These factors were analyzed based on the competitiveness standards used in the furniture industry. To the conjecture of the relationship explication between competitiveness and the two other variables, the interview's data were, in the sequence, exposed to the models: Porter's generic strategies (1986) and the Design's strategies (1993). It was possible to infer from the result of this exposition that the enterprise searches competitive advantage by the differentiation in the former model. And in the second case, there is a predominance of the improved concept utilization.

Key-Words: Design; materials; competitiveness.

\section{Introdução}

O presente artigo procura mostrar como a utilização de materiais para a criação, desenvolvimento $e$ implementação do Design pode contribuir para o incremento da competitividade nas organizações. Neste sentido faz-se uma análise da aplicação dos domínios $e$ estratégias do Design e a sua relação com a competitividade, tomando como referência o segmento moveleiro da Região Metropolitana de Curitiba. Os conceitos de competitividade utilizados estão fundamentados no modelo específico proposto por Ferraz, Haguenauer e Kupfer (1997), que apresentam uma metodologia para analisar pontos fortes e fracos da indústria de países que tentam sobreviver aos efeitos da globalização em um ambiente de concorrência acirrada.

O trabalho é também sustentado a partir do modelo 
genérico de estratégias de Design do Doblin Group Research, que influencia os tipos de produtos de valor agregado proporcionado pelo Design a partir dos objetivos comuns do Design. Assim como, procura posicionar o Design como estratégia de competitividade, incorporando-a à visão do Design às três estratégias genéricas desenvolvidas por Porter (1986): Liderança de Custo, Diferenciação e Enfoque. $A$ análise do modo como as empresas respondem estrategicamente às oportunidades $e$ às ameaças das forças competitivas poderá ajudar às empresas a conhecerem seu ambiente organizacional. Para tanto, procurou-se fazer uma revisão dos conceitos de: Design, materiais para o Design e competitividade. Em seguida é feito um estudo de caso em uma das empresas moveleiras da Região Metropolitana de Curitiba, considerada adequada para a realização da pesquisa, ao mesmo tempo em que, procurou-se classificar as empresas pelo tipo de móvel que fabricam e pelo desenvolvimento ou não do Design próprio. O trabalho se propõe a colocar o Design como instrumento de inovação tecnológica para as empresas da Região Metropolitana de Curitiba enfrentarem, de maneira competitiva, as condicionantes nascidas da "3." Revolução Industrial”, corroborando a prerrogativa de que o conceito ampliado de Design constitui-se num efetivo mecanismo capaz de incrementar a competitividade nas organizações.

O trabalho está assim estruturado, a primeira parte refere-se a fundamentação teórica, na qual são expostos os conceitos e perspectivas das variáveis utilizadas procurando: delinear o cenário de desenvolvimento industrial e econômico contemporâneo; apresentar as áreas de domínio do Design para defini-lo no seu sentido mais amplo, quais sejam, ergonômico, tecnológico, econômico, estético, marketing, social, cultural e ecológico; esclarecer os materiais para o Design de móveis; facilitar a compreensão da competitividade através dos fatores que a determinam e da análise da indústria de móveis do Brasil à luz dos padrões de concorrência praticados no segmento; e, finalizando este capítulo o trabalho apresenta o modelo da utilização do Design como estratégia do Doblin Group Research. A segunda parte descreve a metodologia da pesquisa. Na terceira parte, são apresentados os resultados e análise dos dados coletados e finalmente as conclusões $e$ as considerações finais.

\section{Referencial Teórico}

Design

Houve um tempo em que o trabalho de concepção e o de execução constituíam o "saber-fazer" dos artesãos. Esses herdavam de seus pais o saber transmitido oralmente e pelo conhecimento prático obtido em longos anos de aprendizado. Assim, consolidavam-se ofícios adquiridos por intermédio de conhecimento $e$ experiência de uma longa tradição. Essa experiência tradicional aliada a uma estreita relação artesão/usuário, imbuíam o artesão de funções desde a escolha da matéria-prima e a melhor técnica de conformação, até a fabricação sob medida para a real satisfação do usuário.

Com a Revolução Industrial a partir de 1750, brotam inovações tecnológicas nos processos produtivos que impõem aos artesãos, a máquina e a tarefa repetitiva $e$ descontextualizada. Lembrando Sunkel (1970), da Revolução Industrial emergem conceitos de divisão do trabalho e aplicação dos novos métodos de produção baseados na exploração fabril. Como sustenta Coriat (1976, p.48), “...progressivamente, o capital se assegura do controle e organização da produção científicotécnica". Assim, da separação entre a ciência e a técnica, pari passu, a fusão da arte com a indústria, surge o Desenho Industrial. Para Schulmann (1994, p.13), "No cruzamento de mutações históricas, políticas, econômicas e sociais no cenário de um progresso rápido da tecnologia, o design industrial é, antes de tudo, um fenômeno do século XX."

Para a habilitação na concepção e desenvolvimento de produtos diferenciados e competitivos, racionalizando a produção e visando corresponder com brevidade às preferências e seletividade do usuário/cliente, os conhecimentos do Design compreendem: história da arte e do Design, estética, semiótica, ergonomia, conhecimentos na área tecnológica de materiais e execução de modelos, processos de fabricação, informática, física e domínio das técnicas de representação bidimensionais, além de conhecimentos na área de marketing.

\section{Domínios do Design}

O termo design possui uma variedade de conceitos $e$ interpretações. Essa diversidade não se limita apenas à sua 
definição, ela abrange também a forma com que o Design é percebido pelas pessoas, pelas empresas e pelos países. Gapski et al. (1997) lembram da origem latina da palavra designm - designium (intenção, plano, projeto) que sugere uma abordagem mais ampla e de caráter multidisciplinar do Design, envolvendo todas as etapas do desenvolvimento do produto, da concepção à materialização, sem negligenciar o homem no seu contexto e no seu habitat componente principal desse processo.

A despeito da concepção restrita do Design estar associada a valores estéticos, o Design é uma profissão dinâmica que vem, progressivamente, ampliando o seu espectro de atuação no processo de desenvolvimento industrial e econômico das nações. Como argumenta Antunes JR. (1991), a área de conhecimento de um profissional de Design demanda noções além das de estética e avança para a integração com setores de engenharia e marketing para assumir uma posição responsiva à demanda de mercado, seja pelas rápidas mudanças no produto ou pelo ciclo de vida cada vez mais curto.

De acordo com Cerqueira (1994), a premissa estratégica do Design é a transdisciplinaridade. A atividade do Design coordena aspectos relacionados a diversas áreas, como materiais, sistemas produtivos, tecnologia, mercado, cultura etc. Mesmo que, na época, não reconhecido por esse nome, o designer surgiu com o advento da produção em série, no início desse século. Hoje, o processo do Design, permeia uma área de atuação muito mais abrangente, conforme citado por Guimarães (1999): envolvendo atividades relacionadas ao: Design industrial; o fashion Design; o Design gráfico (Design de interfaces gráficas e embalagens); Design de interiores (móveis e objetos), Design de serviços. Além dessas áreas específicas de concentração do Design, outras vêm se configurando, como ecodesign, Design de softwares e Design social.

Bonsiepe e Walker (1983) propõem um visão sistêmica do Design lembrando que, cabe ao processo de Design o manejo, simultâneo e paralelo de vários parâmetros. Para os autores, na aplicação dos conceitos do Design é preciso levar em consideração aspectos relacionados a várias áreas do conhecimento, tendo como premissa básica a análise das necessidades humanas, envolvendo um conjunto de dados: ergonômicos (antropométricos), tecnológicos (materiais e processos), econômicos (racionalização na produção, custo), sociais (compromisso com o usuário), ambientais (ecologia), antropológicos (culturais, design autóctone) e estéticos, além dos fatores psicológico - emocionais (tendências), éticos (social, ecológico) e de marketing. A figura abaixo expõe a visão multidisciplinar do Design, expondo os seus vários domínio:

\section{materiais}

A utilização de recursos naturais pelas necessidades humanas decorre do maior entendimento da natureza dos materiais, sua estrutura e composição, das formas de processamento e da destreza em transpor esses conhecimentos, com capacidade criativa, ao projeto de Design e por conseguinte ao produto final. Esse necessário relacionamento entre homem e natureza estabelece um circuito evolutivo de conhecimento, que se estende desde as experiências da sociedade (conhecimento empírico) até a ciência básica e à pesquisa fundamental (conhecimento científico).

O trabalho do Design na transformação de matériaprima em produtos e bens de consumo é o de intermediário entre o conhecimento e a produção. $E$ o agenciamento das tendências de consumo da sociedade, abrangendo a função do produto sob o aspecto tecnológico, econômico e sociocultural. Sobretudo, compete ao Design a racionalização do processo de produção, viabilizando a eficácia produtiva pelo emprego de métodos científicos. Para Passos(1999) a dinâmica do sistema econômico repousa fisicamente na demanda dos produtos e bens de consumo.

\section{Os materiais para o Design de móveis}

Conforme escreve Ferreira (1986): móvel (do latim mobile) significa inconstante, variável, volúvel, peça de mobília, este último é termo relativo aos objetos para uso ou adorno interior de uma casa ou ambiente. Assim, o Design de móveis se ocupa do desenvolvimento de produtos utilizados pelo homem para repousar seu corpo ou para guardar seus pertences, produtos esses que compõem a mobília no seu ambiente doméstico ou de trabalho. Historicamente, muitos foram os materiais empregados pelo homem na fabricação de móveis, dentre os mais constantes estão a madeira, o ferro e o bronze como materiais estruturais. Matérias-primas virgens, tais como couro, osso, fibras naturais, madrepérola, metais e pedras preciosas, tecidos, tintas e vernizes são relacionados com emprego decorativo nos móveis. 
Atualmente, a indústria moveleira utiliza, sobretudo, materiais de natureza sintética e artificial como os polímeros reforçados com fibras de vidro ou na forma de laminados plásticos para acabamentos em chapas de madeira. O surgimento da espuma de poliuretano impulsionou o setor de estofados, substituindo com eficiência as fibras naturais de crina de cavalo, até então, utilizadas para assentos e encostos. Os metais também são solicitados pelos fabricantes de móveis,

principalmente na forma de tubos estruturais e componentes de mecanismo. Materiais alternativos como vime e junco vêm contribuindo para o desenvolvimento de tecnologia (produtos e processos inovadores) na área de móveis.

A preocupação com a devastação das florestas de madeiras nativas e suas conseqüências no equilíbrio da biodiversidade levou alguns mercados à restrição ou uso parcimonioso da utilização de madeiras nobres como matéria-prima para o fabrico de móveis. Positivamente, essa imposição ecológica remeteu o setor moveleiro para emprego de novos materiais como o MDF (Medium Density Fiberboard) e novas matérias-primas como as madeiras reflorestadas.

O emprego de novas matérias-primas estimulou a utilização combinada de materiais, ou seja, a conjugação de diferentes materiais na confecção do mesmo móvel. Entre os materiais mais comuns utilizados de "forma combinada" num móvel destacam-se, além da madeira maciça e dos painéis de madeira (lâminas, compensados, aglomerados, chapas de fibras e MDF), o metal, o couro reconstituído, os polímeros e as borrachas, o vidro, a pedra (mármore ou granito), o vime e o junco.

Nahuz (1998) comenta: "o uso de madeira não tradicional para o mercado moveleiro, como é o caso do eucalipto, requer a integração de elementos de design". Muitos dos tradicionais defeitos que impediam o uso do eucalipto como matéria-prima no segmento moveleiro são, hoje, caraterísticas que podem ser manipuladas tecnologicamente com soluções simples. Por exemplo, o diâmetro pequeno das árvores de eucalipto (crescimento rápido) geram tábuas estreitas incompatíveis com Design de formas retilíneas. $A$ integração entre $P \& D e$ Design resultou na introdução de eucalipto no segmento de móveis por meio de chapas sarrafiadas e coladas.

Além de baratear o custo final, preservando o mesmo patamar de qualidade, a relação entre o uso de novos materiais e as novas técnicas produtivas proporciona a modernização dos processo de fabricação e a inovação do produto, que emergem com o aprimoramento do Design.

\section{Competitividade}

A visão de competitividade pode ser obtida através dos conceitos mercadológicos de Kotler (1994) e de estratégias competitivas de Porter (1986) na qual a base do conceito e da aplicação da competitividade são valor e utilidade dos produtos e dos serviços. O valor é o grau de utilidade que um bem tem para seus clientes. A utilidade surge de um conjunto de fatores que geram benefícios para os compradores, podem ser elementos que aumentam o desempenho ou que contribuem para a diminuição de custos. $O$ produto, com suas características específicas, é oferecido a um segmento de compradores, os quais - a partir de determinado perfil de necessidades - o valorizam e manifestam interesse em pagar determinado preço. O preço que estarão dispostos a pagar surgirá tanto de avaliações de caráter subjetivo, quanto da comparação com outros produtos semelhantes. O lucro da empresa depende da relação que se estabelece entre seus custos e o valor gerado para o comprador e as conclusóes deste de quanto deve pagar. É função da estratégia a gestão dos elementos geradores de valor pois, em princípio, quanto maior o valor percebido pelo comprador, maior é o preço que a empresa pode cobrar, e maior a rentabilidade.

Para avaliar a competitividade de uma empresa, segundo Paladini (1997) é preciso estabelecer um conjunto de indicadores que utilizem como referência as variáveis agrupadas nos seguintes blocos: desempenho, capacitação, estratégia. Os indicadores de desempenho referem-se à avaliação do processo produtivo, envolvendo as fragilidades e potencialidades da organização mediante a medição da eficiência da empresa. Os indicadores de capacitação referem-se à organização como um todo, atuando como medidores das ações de apoio ao processo produtivo. Os indicadores da estratégia abrangem procedimentos de gestão estratégica que acompanham as mudanças de mercado com a medição da eficácia.

Quando a competitividade é relacionada ao desempenho ou à eficiência das empresas, temos definições de enfoques estáticos, uma vez que estes analisam o comportamento passado dos indicadores. 
A competitividade como variável ex-post é revelada mediante o desempenho alcançado no mercado por uma empresa em um determinado tempo, cujo indicador é participação nas exportações e sua posição competitiva é definida pela demanda; a competitividade potencial é uma variável ex-ante, vista como eficiência produtiva, cujos indicadores são as melhores práticas e a capacitação tecnológica reflete a competitividade da empresa.

O nível de capacitação acumulado nas áreas da competência empresarial: gestão (tarefas administrativas), inovação ( $P \& D$ em processo e de produtos), produção (equipamentos e organização da produção) e recursos humanos determina o desempenho competitivo. Como o nível de capacitação depende dos investimentos em estratégias competitivas, deve-se buscar os elementos analíticos da competitividade no processo de decisão das estratégias empresariais. Assim, Ferraz, Haguenauer e Kupfer (1997) apresentam uma visão dinâmica da competitividade na qual, o desempenho no mercado e a eficiência produtiva decorrem da capacitação acumulada pelas empresas que, por sua vez, reflete as estratégias competitivas adotadas em função de suas percepções quanto ao processo concorrencial e ao meio ambiente econômico onde estão inseridas, considerando a empresa como um todo e apresentam caráter dinâmico, acompanhando as transformações vividas no atual cenário econômico mundial.

\section{Indicadores de competitividade na Indústria Moveleira na Perspectiva da Aplicação das Técnicas de Design e Utilização de novos materiais}

Para analisar a aplicação dos domínios e estratégias do Design e a sua relação com a competitividade, tomando como referência o segmento moveleiro da Região Metropolitana de Curitiba, fez-se necessário o conhecimento do seu nível de estruturação. Este conhecimento servirá de base ao estudo de caso proposto pela pesquisa em questão. Fundamentou-se, então, em uma metodologia de análise das potencialidades $e$ limitações da produção que, quando são vantajosas para a empresa e para o País, aumentam a quantidade $e$ qualidade da produção e do emprego.

A metodologia procura mapear, através da análise da trajetória da produção industrial, desafios competitivos. Os esforços exigidos para enfrentar estes desafios dependem do padrão de concorrência vigente em cada grupo da indústria brasileira: commodities, bens duráveis, tradicionais e difusores de progresso técnico. Cada um desses grupos comporta um conjunto de segmentos compostos por setores industriais, quais sejam, respectivamente: insumos metálicos (siderúrgica), química básica (petroquímica), agroindústrias de exportação (suco de laranja), celulose e papel; automotivo (autopeças) e eletrônico; agroindústrias de alimentação (laticínios), têxtil-calçados (vestuário) e mobiliário (móveis de madeira); equipamentos eletrônicos (computadores) e eletromecânicos (máquinas-ferramentas).

Assim, pode-se estabelecer o nível de estruturação do segmento moveleiro da Região Metropolitana de Curitiba da seguinte forma:

- grupo tradicional: os produtos fabricados pela indústria moveleira estão classificados como bens tradicionais;

- segmento mobiliário: abrange setores vinculados por bases tecnológicas semelhantes, mercados afins, compra $e$ venda de insumos etc.;

- setor de móveis estofados, móveis de chapas retilíneas, móveis torneados, móveis para escritório, residenciais de madeira etc.

O segmento moveleiro, de interesse deste trabalho, encontra-se no grupo das indústrias tradicionais, que congrega empresas que manufaturam produtos destinados ao consumo final da população em geral, como indústrias alimentares e todos os setores do complexo têxtil/vestuário/calçados.

As indústrias tradicionais são caracterizadas pela diversidade de produto e de empresas com portes variados e diferentes níveis de desempenho e capacitação produtiva. O padrão de concorrência é de segmentação de mercados e a posição competitiva da empresa é definida pela eficácia e eficiência da gestão. O setor é usuário de inovação gerada fora dele, sendo que bens de capital e insumos não diferenciam as empresas. As barreiras à entrada de novos concorrentes são baixas e as empresas com práticas produtivas de menores custos $e$ maior adequação ao uso do produto tendem a expandir em relação às demais. 


\section{Diagnóstico da Indústria Moveleira Brasileira e os Padrões de Concorrência Praticados no Segmento}

As tendências competitivas das empresas moveleiras de sucesso internacional dizem respeito ao elevado grau tecnológico dos equipamentos, à especialização produtiva, ao aprimoramento do Design e às estratégias agressivas. A primeira tendência, substituir máquinas com dispositivos eletromecânicos por microeletrônicos implicando melhorias no processo produtivo, controle da qualidade dos produtos e vantagens, sobretudo para empresas orientadas para processos de produção flexíveis.

A especialização produtiva é resultado da evolução do padrão internacional de organização da indústria de móveis para redução da verticalização da produção, onde as empresas maiores dedicam-se à montagem e ao acabamento de móveis a partir de peças e componentes produzidos pelas pequenas empresas que trabalham em regime de subcontratação. No modelo tradicional da indústria de móveis, cada unidade produtiva era responsável por inúmeros processos e obtinha uma multiplicidade de produtos.

O Design e a utilização de novos materiais refletem inovações de produto. Os materiais para a indústria de móveis dependem do progresso técnico exógeno; por exemplo, as chapas de MDF são desenvolvidas pela indústria de madeira aglomerada. Por outro lado, a indústria moveleira encontra no Design um instrumento próprio de inovação de produto. Tanto o aprimoramento do Design como a maior flexibilidade na criação de modelos se devem à introdução de equipamentos de base microeletrônica, como o sistema CAD (Computer Aided Design).

\section{O Modelo Doblin Group Research e as estratégias de Design}

Para evidenciar o Design no interior da organização como instrumento de competitividade, o trabalho tomou como modelo as estratégias de Design do Doblin Group Research que, por sua vez, são baseadas no modelo estratégias competitivas de Porter (1986), o qual possui três estratégias genéricas que são métodos para lidar com as forças competitivas, são elas: a liderança através da redução de custos, pela diferenciação e pelo enfoque. Com base no modelo genérico de Porter o grupo de estudo do Design, o Doblin Group Research, postulou as estratégias genéricas para o Design dentro da empresa, apresentadas no tópico seguinte.

Um produto de valor agregado proporcionado pelo Design, é aquele que reflete a interação do Design com as leis de mercado e com as necessidades e desejos do usuário. Desta forma o Doblin Group Research, um grupo de consultoria em Design com sede em Chicago, agrupou as sete principais preocupações de Designs bem-sucedidos, quatro quanto ao usuário e três quanto ao mercado, quais sejam, respectivamente, conveniência, entendimento, interesse, conforto, durabilidade, concordância e valor.

Mediante a análise desses requerimentos do Design e dos pontos fracos existentes nas estratégias organizacionais, o grupo americano desenvolveu o modelo genérico de estratégia do Design que determina dentro de um espaço de tempo e um mercado específico, o vencedor e o perdedor, mediante a análise do mercado e reconhecimento de suas transformações no tempo. Assim, o modelo traça um mapa das transformações importantes para os usuários e para o mercado e da integração do Design dentro das empresas para redefinir ou equilibrar as suas estratégias.

Os conceitos das quatro estratégias genéricas de Design são:

- aperfeiçoado: expressivo aperfeiçoamento sobre o status-quo; mudança mais fácil de se atingir; apresenta bom resultado quando este é melhor que os substitutos disponíveis no mercado;

- estendido: transforma uma estratégia existente em meio de surpresas; resulta de um mercado consolidado, evolutivo e de mudanças diárias;

- de invenção: princípio novo aplicado na abertura de novos mercados ou para criar novas fatias dos mesmos; vencedores podem se tornar perdedores;

- integrado: conjuga habilidades comuns (serviço pósvenda); adequação de uma tecnologia para explorar novos mercados.

O modelo genérico de estratégias do Design do Doblin Group Research considera a capacidade e a estrutura das organizações. A capacidade de uma organização é representada pelas habilidades de mudança que esta possui para alterar propriedades, serviços, processos, 
posicionamento e expectativas da marca dos produtos que desenvolve. Os produtos de conceitos integrados $e$ aperfeiçoados contam com capacidades correntes, enquanto que os conceitos de invenção e estendido necessitam de novas capacidades.

As estruturas organizacionais são difíceis de serem mudadas, pois para que isto ocorra é preciso haver modificações nas expectativas do consumidor, na prática de oferta de serviços, nas vendas, nos sistemas de informação etc. Assim, integrado e invenção são conceitos que precisam de uma nova estrutura, enquanto que os conceitos aperfeiçoado e estendido são satisfeitos com a estrutura comum.

A partir da apresentação, sobretudo dos domínios do Design, dos materiais e da competitividade, foi estabelecido o referencial teórico, que serviu como um marco para o estudo de caso, cujo problema consistiu na identificação do grau de utilização dos materiais para a criação, desenvolvimento e implementação do Design e a posição competitiva do segmento moveleiro da Região Metropolitana de Curitiba, levantados a partir da observação não participante em várias empresas e entrevista semi-estruturada com o diretor da empresa selecionada para o estudo de caso.

\section{Metodologia do Trabalho}

Para avaliar a utilização dos materiais no Design de uma empresa do segmento moveleiro e diagnosticar o seu grau de competitividade foi aplicada a pesquisa qualitativa e utilizada a técnica da observação nãoparticipante e entrevista semi-estruturada. $O$ universo da pesquisa refere-se às empresas da Região Metropolitana de Curitiba, as quais se utilizam, de forma factível, do Design como instrumento de competitividade das empresas.

Para definir o perfil e o tamanho da amostra para a pesquisa de campo foi considerado como universo de análise a relação dos municípios da Região

Metropolitana de Curitiba, com empresas moveleiras cadastradas no relatório sintético das empresas do Sindicato da Indústria do Mobiliário e Marcenarias do Estado do Paraná - SIMOV. A partir daí, foram definidos alguns critérios para definição do tamanho da amostra, foram eles:

- cadastro no relatório do SIMOV;
- localização na Região Metropolitana de Curitiba;

- possuíssem fabricação própria;

- tivessem um quadro de empregados superior a 10 pessoas;

- utilizassem efetivamente o Design como estratégia para competitividade.

Em função destes critérios a amostra ficou constituida por 30 empresas. Foram feitos contatos por telefone com cada uma delas, para conhecer o interesse das empresas em participar do trabalho e para definir o perfil das empresas componentes da amostra.

Para avaliação do último critério para definição da amostra foram consultados o SIMOV e o designer responsável pelo Programa de Extensão Tecnológica para a Área de Design de Produtos, financiado pelo PATME - Programa de Apoio Tecnológico às Micro e Pequenas Empresas - um mecanismo criado pelo SEBRAE e a FINEP para permitir que se possa acessar os conhecimentos existentes no País, através de consultorias, visando à elevação do patamar tecnológico da empresa. A partir daí, todas as empresas foram visitadas e analisadas em função do estabelecido no referencial teórico do trabalho e escolheu-se a empresa mais representativa em termos de prática do Design, da utilização de novos materiais, além de uma efetiva preocupação com o seu grau de competitividade, escolheu-se uma empresa para ser o referencial para o estudo de caso.

\section{Apresentação e Análise dos Resultados}

Fundada em 1919, a empresa estudada recentemente passou por uma reformulação de linha de seus produtos, passando de um Design tradicional para um contemporâneo e moderno. A empresa vem investindo, ocupando espaços que vão se formando pelo recuo de outras concorrentes que se retraem, sendo este um dos motivos pelos quais elegeu-se esta empresa como objeto de estudo da pesquisa.

\section{Processo Produtivo e Instalações}

Situada na Região Metropolitana de Curitiba, a empresa é dividida em três unidades: espumas e colchões, móveis 
e show room, com um número total de 300 funcionários. A Unidade Móveis emprega $50 \%$ desses funcionários e é composta por quatro setores: beneficiamento, metalurgia, corte e estofamento.

O processo produtivo tem início com o recebimento de tábuas de madeira maciça, sendo $90 \%$ de eucalipto $e$ $10 \%$ de imbuia. Respeitando as exigências ambientais quanto à redução do uso de madeira nativa, há sete anos a empresa introduziu o eucalipto (madeira de reflorestamento), e vem melhorando gradativamente quanto ao seu manuseio. As madeiras classificadas como de $3 .^{a}$ qualidade são empregadas nas estruturas dos estofados enquanto que as madeiras de $1 .^{a}$ são utilizadas na fabricação de móveis. As tábuas ficam dispostas no pátio por aproximadamente 4 a 5 meses para secar.

Quando as tábuas atingem o grau de umidade entre 12 a $16 \%$, elas são encaminhadas para o setor de beneficiamento. Passam então, pelas seguintes máquinas: desengrossadeira e rebote para esquadrejamento, serra circular para o corte de peças retas como ripas e tocos, serra fita para peças com curvas como as moldadas que são desdobradas mediante o uso de moldes de madeira.

Ainda no setor de beneficiamento, as madeiras são acondicionadas em containers, sendo que cada caixa é preenchida com peças para a execução da estrutura de um determinado modelo de estofado. A empresa movimenta dois containers por modelo, enquanto um deles alimenta a célula de trabalho, o outro está sendo abastecido no setor de beneficiamento, ou seja, não há ordem de serviço e a otimização do processo se dá mediante o uso de kanban.

$O$ destino dos containers são as células de trabalho que consistem numa equipe composta por 4 trabalhadores polivalentes que se alternam nas funções de montagem do estofado, quais sejam, montar a estrutura de madeira, colar a espuma de poliuretano, encapar e grampear o tecido e por último embalar o móvel pronto. Como pode-se observar, a célula terminal representa uma mini fábrica, onde se transformam matérias-primas em produtos acabados. Percebe-se também que, além da estrutura que pode ser em madeira ou metal, da espuma para o assento e do tecido para a cobertura, cada modelo de estofado é composto por suas partes, peças e componentes. Como o desenvolvimento do trabalho em célula não pressupõe a saída dos seus trabalhadores do perímetro da mesma, são os volantes (auxiliares de produção) que estabelecem a ponte entre as células terminais e as células interligadas de cada modelo de estofado. A empresa conta com 5 células interligadas, responsáveis pelo abastecimento das células: beneficiamento, ensacamento de almofadas, corte de tecido, montagem de peças de gabarito e componentes.

Para o assento do móvel, a empresa recebe a espuma de poliuretano já cortada, a qual é envolvida numa fibra de poliéster. Para o encosto, são utilizadas fibras siliconizadas, que têm a propriedade de memória e após a compressão retornam à forma original. As almofadas são ensacadas e pesadas, pois as fibras devem ser distribuídas de forma regular para garantir o conforto homogêneo em toda a extensão do encosto.

A empresa trabalha com $50 \%$ de tecidos nacionais e $50 \%$ de tecidos importados, principalmente da Holanda e da Coréia. Eles são cortados mediante o uso de moldes prédeterminados e levados para costura, outra atividade que a empresa terceiriza. Para garantir a qualidade, sobretudo do acabamento de seus produtos, a empresa oferece treinamento para costureiras que, antes de desenvolverem esta atividade em suas casas, participam de estágios que variam de dois a três meses.

A empresa também conta com um setor de prototipação que foi muito bem definido pelo funcionário lá presente: "aqui o sofá sai do papel". Neste local são feitos testes de materiais, volume, peso e possibilidades de fabricação das peças.

Mesmo sendo em madeira, algumas estruturas apresentam maior complexidade e precisam ser executadas em células interligadas de montagem de peças de gabarito. As estruturas de tubo metálico para os estofados, assim como alguns componentes, provêm da metalúrgica do grupo, instalada no próprio parque industrial. O tubo metálico que a empresa mais trabalha é o 1020. Após ser cortado na serra, o material é encaminhado para uma máquina dobradeira de comando computadorizado; na seqüência $e$ dependendo da utilização da peça, estão as etapas de furação, estamparia e outras. Beneficiados os tubos são soldados (solda MIG) em cabines especiais. Montadas as estruturas, estas seguem para tanques de limpeza, onde os metais são desengraxados, desoxidados e decapados. Peças que não serão expostas no móvel são pintadas com tinta líquida, aplicada com pistola. Peças de maior exposição recebem revestimento epoxídico, sendo a peça pulverizada em câmara eletrostática, seguindo para o 
forno, onde a uma temperatura de aproximadamente $180^{\circ} \mathrm{C}$, o polímero adere à peça por meio da cura térmica.

Embora a empresa mantenha nas suas instalações uma marcenaria auxiliar para pequenos ajustes ou trabalhos auxiliares, a fabricação de móveis (camas, mesas, consoles, racks, cristaleiras, criado, estante etc.) é terceirizada em três marcenarias. A empresa, assim, encarrega-se da montagem e acabamento desses produtos. Para isso, ela mantém um setor de lixamento, cabine de envernizamento e de tingimento de madeira nos padrões marfim, imbuia e laca.

Convém ressaltar os aspectos positivos oriundos da modernização organizacional produtiva pela qual a empresa passou, sobretudo, quanto à celulização do processo produtivo. No modelo antigo de linha de produção, os setores de beneficiamento e montagem ficavam abarrotados de esqueletos e de estruturas pré montadas, que apesar do seu volume seguiam para o setor de espumas, ou seja, circulavam pela indústria muitos móveis semi-acabados, que além de ocupar muito espaço físico retardavam o processo produtivo, formando gargalos na produção. Com introdução das células e dos cartões de kanban que priorizam o abastecimento dos containers, a empresa racionalizou o processo de produção, transformando matéria-prima em produto acabado just-in-time, ou seja, de forma sincronizada com a demanda de mercado. Facilitando também a adaptação às mudanças de mercado, o que se reflete, ao nível produtivo, na troca de ferramentas ou setup de produção. Pois, além dos doze modelos lançados anualmente, a empresa apresenta uma resposta rápida (quick response) à substituição dos modelos menos vendidos ou aqueles copiados por marcenarias informais e que saturam o mercado.

Outro aspecto é quanto ao efetivo de mão-de-obra que reduziu em 20\%, enquanto que a produtividade aumentou para $30 \%$. O ciclo de produção diária de uma célula terminal, ou seja, da matéria-prima dos containers até a embalagem da peça é, em média, de dez produtos acabados. Esse escore se deve em grande parte a participação da equipe nos ganhos, que a empresa oferece pelo aumento da produtividade da célula. Notável, também, é o processo contínuo de aperfeiçoamento e qualificação de mão-de-obra especializada que a empresa desenvolveu a partir das células de trabalho. Praticamente, quanto a contratações do efetivo da produção, a empresa só se preocupa com auxiliares de produção. Estes, sempre que possivel, estão contribuindo dentro das células ou observando o trabalho da equipe, ou seja, estão treinando e almejando novas funções.

\section{Análise dos Resultados}

Nesta parte do trabalho são evidenciados, na vivência prática de uma empresa, os conceitos e variáveis levantados a partir do referencial teórico. Trata-se de uma abordagem que envolve questões relativas à competitividade, ao Design, aos materiais e às estratégias de Design e de Porter. Conforme o conteúdo da entrevista, os principais pontos consonantes ao referencial teórico são:

1. o princípio atual da empresa é manter a qualidade dos seus produtos e para mantê-la a ordem é diferenciar através do Design;

2. no seu processo produtivo é possivel identificar as melhores práticas de trabalhos, quais sejam: kanban, células de produção, polivalência e multifuncionalidade dos empregados, terceirização, treinamento $e$ capacitação etc.;

3. a estratégia de produção está relacionada com a busca de uma produção horizontalizada;

4. tem uma preocupação com a segmentação do mercado (baseado em faixas de prę̧o dos seus produtos);

5. sente a necessidade de lançar novos produtos com um apelo mercadológico baseado na diferenciação;

6. o maior responsável pela atual estratégia da empresa tem sido a utilização do designer;

7. utiliza tecnologias tradicionais e avançadas, concomitantemente;

8. a utilização dos trabalhos do designer permitiu melhorar os aspectos ergonômicos e funcionais dos produtos;

9. existe uma conjunção entre as atividades do designer, o proprietário e os clientes da empresa;

10. "o preço está em segundo plano, em primeiro lugar está o Design, a exclusividade, a diferenciação; 
11. os empregados são, de modo geral, polivalentes e multifuncionais;

12. boa parte do processo produtivo é terceirizado;

13. não utiliza uma tecnologia específica muito apropriada para o tipo de atividades desenvolvidas, no caso, o $C A D / C A M$;

14. não participa de alianças tecnológicas, pólos ou economia de agregação;

15. tem uma preocupação com a renovação dos equipamentos;

16. participa de feiras nacionais e internacionais;

17. tem preocupação com o treinamento e capacitação dos seus empregados;

18. o canal de comercialização mais comumente utilizado tem sido feito junto a revendedores;

19. é usuária de inovação de materiais e de máquinas gerada fora da empresa, ou seja, seus produtos não são diferenciados por esses fatores, uma vez que esses estão igualmente disponiveis às empresas concorrentes;

20. o processo artesanal do setor e a facilidade de acesso às matérias-primas não impõem barreiras à entrada de novos concorrentes;

21. informações sobre as preferências dos mercados são fornecidas pelos lojistas e tendências internacionais.

A partir destes pontos, pode-se fazer as seguintes considerações:

- a empresa parece ter uma preocupação com os diversos domínios do Design;

- tomando como referência o modelo de estratégia competitiva de Porter, o teor da entrevista mostra que a empresa busca a vantagem competitiva através da diferenciação;

- no que se refere ao modelo genérico de estratégias de Design, podemos inferir que há uma predominância na utilização do conceito aperfeiçoado.

Conforme as informações obtidos na entrevista e na visita ao parque industrial podemos traçar o perfil da empresa estudada quanto a aplicação dos domínios e estratégias do Design e a sua relação com a competitividade, a partir $d a$ análise dos pontos convergentes e divergentes em relação às tendências explicitadas no referencial teórico deste trabalho, a saber:

1. atualização de equipamentos: Apesar da empresa conjugar tecnologias tradicionais e avançadas na mesma planta industrial, o grau de modernização tecnológica em máquinas e equipamentos no setor de estofados é bem menos acentuado do que nos outros setores do segmento moveleiro. A tecnologia tradicional é percebida na montagem dos móveis estofados. Conforme o relato do gerente a fabricação de estofados continua, ainda, sendo $90 \%$ artesanal, sendo que o único avanço tecnológico foi o desenvolvimento da grampeadeira pneumática. $O$ incremento tecnológico se encontra nas máquinas CNC para cortar a madeira $e$ para dobrar os tubos metálicos, materiais componentes da estrutura do estofado, e no equipamento de solda de última geração.

2. inovações organizacionais: De forma compativel aos padrões de concorrência observados nas empresas portadoras das melhores práticas, a empresa vem substituindo o sistema convencional pelo novo paradigma produtivo. A fábrica sofreu uma reestruturação do seu layout, onde foram adotadas células de trabalho abastecidas por técnicas de just-in-time, kanban e polivalência de funcionários. Acompanhando, sobretudo às tendências das empresas italianas líderes mundiais em Design, a empresa especializou sua produção na montagem e acabamento de estofados, além dos móveis complementares produzidos em menor escala. A adoção desse procedimento reduziu a verticalização da sua produção e favoreceu a implementação e aprimoramento do Design.

3. Design: A despeito da empresa não manter em suas instalações um departamento de Design formalmente constituído, uma vez que a empresa se utiliza de consultoria nessa área, percebe-se que o trabalho de desenvolvimento de produtos da empresa é direcionado para concepção ampliada do Design. A busca pelo atendimento dos diversos domínios do Design parece ser uma preocupação constante no desenvolvimento dos móveis estofados da referida empresa, assim observados:

- a empresa realiza levantamentos antropométricos periódicos que garantem os aspectos ergonômicos;

- em sincronia com as exigências ambientais, a empresa substituiu, em grande parte, o uso de madeiras nativas por reflorestadas; 
- a adoção de inovação tecnológica na organização da produção refletiu flexibilização e otimização no processo produtivo, permitindo à empresa responder de forma mais rápida às mudanças exigidas pelo mercado;

- a empresa também demonstra habilidade em concretizar os condicionantes técnicos e funcionais em conjugação com os valores estéticos;

- os aspectos econômicos do Design são lembrados pelo gerente da empresa na padronização e redução do número de componentes e volume do móvel para efeito de transporte e redução de avaria.

Entretanto, são nas áreas de domínio social, cultural e marketing do Design que a empresa encontra dificuldades. Apesar da designer ter feito uso de um estudo mercadológico prévio ao desenvolvimento de produtos, o gerente deixa bem claro em suas respostas que as informações sobre as preferências dos mercados são fornecidas pelos lojistas e pelas tendências internacionais. Este fato distancia o usuário final do móvel, referência maior para o desenvolvimento de Design cultural e social, da participação e do envolvimento no projeto. O compromisso do Design social de móveis em atender as preferências do usuário é baseado nas reais necessidades do consumidor final $e$ este conhecimento se obtém pesquisando-se a rotina da família. Quando o Design de móveis é adaptado às necessidades das residências brasileiras, por exemplo, temos o Design autóctone de uma determinada região.

4. materiais: Segundo o referencial teórico deste trabalho, a principal matéria-prima utilizada no segmento mobiliário é a madeira transformada (aglomerado e MDF) conjugada com a madeira maciça. Diversamente de outros setores do segmento mobiliário, a matéria-prima básica para a fabricação de estofados é a espuma de poliuretano que representou um dos maiores avanços tecnológicos na fabricação de estofados, quando substituiu as fibras naturais no preenchimento das almofadas.

Outro material de importância igualitária à espuma, sobretudo na composição do custo do estofado é o tecido, que somado ao poliuretano é responsável por $70 \%$ do custo do móvel.

Em consonância com o estímulo à utilização de madeiras reflorestadas e ao domínio do Design referente a eficiência ecológica, a empresa introduziu o eucalipto na armação de sofás. A empresa justifica o fato de não estar envolvida com programas de reflorestamento por considerar a madeira uma matéria-prima secundária no fabrico de seus produtos.

No tocante ao uso dos materiais para criação, desenvolvimento e implementação do Design, percebese que a empresa depende do avanço tecnológico das empresas fornecedoras, seja no desenvolvimento de novas matérias-primas, como a espuma de poliuretano, ou no fornecimento de padronagem de tecidos. Este fato, como sustenta o entrevistado, contribui para estabelecer baixas barreiras à cópia do produto pelos concorrentes, uma vez que esses têm acesso às mesmas matérias-primas. A seleção dos materiais para o desenvolvimento do produto se caracteriza, assim como um forte aliado no aprimoramento e implementação do Design, elemento responsável pela diferenciação do móvel estofado.

\section{5. segmentação de mercado e diferenciação do} produto: Espelhando-se no padrão internacional, a empresa estudada adotou a estratégia de segmentação de mercado. Para ela, o preço está em segundo plano, em primeiro lugar está o Design, a exclusividade e a diferenciação. Conforme salienta o entrevistado, a fabricação do estofado "exige pouco investimento tecnológico e qualquer fundo de quintal pode fazer um sofá parecido com o nosso utilizando-se da mesma cobertura que é o que vai dar a maior característica de similaridade e usando o mesmo tecido, parece tudo igual." Neste cenário, antecipando-se aos seus concorrentes a empresa promove lançamentos anuais de modelos com expressivo aperfeiçoamento, renovando sua imagem no mercado e reforçando sua capacitação inovativa como vantagem competitiva.

\section{Conclusões, Recomendações e Limitações do Trabalho}

A pesquisa desenvolvida buscou analisar a aplicação dos domínios e estratégias do Design e a sua relação com a competitividade, tomando como referência o segmento moveleiro da Região Metropolitana de Curitiba, em função da utilização dos materiais na criação, desenvolvimento e implementação do Design, a partir de um estudo de caso numa empresa metodologicamente selecionada.

O estudo de caso possibilitou o levantamento dos fatores 
de sucesso da empresa e a sua comparação com os padrões de concorrência internacionais para identificação do seu grau de competitividade conjugado a três fatores: atualização dos equipamentos $e$ especialização produtiva, Design e materiais, estratégias de diferenciação e de Design.

Para acompanhar a dinâmica do mercado é preciso investir em equipamentos e métodos de produção. Com base nas respostas obtidas do gerente da empresa $e$ mediante visita às instalações e acompanhamento do processo produtivo, percebe-se que a empresa acompanha a dinâmica do mercado investindo em métodos de produção. Entretanto, a sua unidade móveis não investe em equipamentos para assegurar o crescimento sustentado da produtividade, por acreditar que no ramo de estofaria ainda há o predomínio do processo artesanal.

A especialização produtiva é reflexo da evolução dos métodos de organização da indústria para horizontalizar sua produção. Mediante a análise dos dados levantados pode-se dizer que, de forma consonante às tendências do padrão internacional, a empresa reestruturou seu layout para dedicar-se à montagem e ao acabamento de móveis a partir de peças e componentes fornecidos, na maioria das vezes, por empresas que trabalham em regime de subcontratação.

O Design e a utilização de novos materiais resultam em inovações de produto. Em função de adotar uma configuração industrial desverticalizada, onde são privilegiadas as atividades de montagem e de acabamento de móveis, a empresa encontrou na consultoria em Design um instrumento próprio de inovação de produto, demonstrando preocupação constante com os diversos e diferentes domínios do Design. Mesmo que nem todos os domínios tenham sido contemplados na sua plenitude, pois percebem-se algumas deficiências nos aspectos social e cultural do Design, a empresa se mostra suscetivel e favorável à solução de suas falhas.

No tocante ao uso de novos materiais, no entanto, a indústria depende de progresso técnico exógeno. Um dos fatores propulsores para a realização desta pesquisa foi a avaliação da importância do uso dos materiais na prática do Design como estratégia da competitividade no ambiente industrial. Da realização da entrevista com o gerente da empresa estudada, conclui-se que o material é uma variável dependente dos avanços tecnológicos oriundos de fontes externas à empresa. Entretanto, este fato não anula a importância da seleção dos materiais na estratégia de Design. Ao contrário, salienta a sua relevância, na medida que expõe as empresas ao mesmo nível de concorrência fundamentado na eqüidade no acesso à tecnologia dos materiais disponível. Ou seja, as empresas fabricantes de estofados compartilham do mesmo leque de fornecedores de materiais, sobretudo do setor têxtil, situação esta que confirma e fortalece a prática do Design na diferenciação de seus produtos.

Os estudos realizados também permitem concluir que, a despeito de no setor de móveis a marca não ser usada para diferenciação no processo de concorrência, a empresa demonstra preocupação em fixar sua marca mediante estratégia de diferenciação por segmentação de mercado por renda.

No que se refere à estratégia de Design, a partir dos dados levantados pode-se inferir que a empresa apresenta habilidades para alterar propriedades, processos e posicionamento dos seus produtos com a capacidade e estrutura organizacionais correntes, características do conceito aperfeiçoado do modelo genérico de estratégias do Design.

O estudo ora apresentado não se esgota em si mesmo. Caracteriza-se como um canal aberto para novas pesquisas envolvendo a área de Design, aprofundando alguns pontos e ampliando o número de variáveis utilizadas. Algumas das dificuldades encontradas no decorrer da pesquisa e que não puderam ser tratadas transformaram-se em contribuições para a realização de possiveis e novos trabalhos:

a. ampliação do foco do estudo de caso, abrangendo outras empresas, o que permitiria um diagnóstico do Design de móveis no segmento moveleiro;

b. levantamento do sucesso elou fracassos das empresas na criação, implementação e desenvolvimento do Design.

Outra possibilidade de pesquisa seria a contextualização dos domínios do Design, na esfera industrial, na busca da real satisfação dos desejos e necessidades da sociedade para criar qualidade de vida. Esta possibilidade abarca, sobremaneira, a importância do desenvolvimento do Design próprio de uma empresa, sua contribuição para a melhoria na qualidade de vida de uma sociedade e para 
o desenvolvimento da nação que a acolhe. Estamos nos referindo aos domínios do Design: cultural e social. Trata-se portanto, dos dois domínios, cuja abrangência por parte da empresa, por nós estudada, é deficitária.

Uma das contribuições deste trabalho é fornecer à empresa pesquisada uma visão externa acerca do grau de competitividade que ela possui para ajudá-la a entender seus concorrentes e sua própria posição quanto ao uso $e$ benefício efetivos do Design como estratégia de competitividade.

\section{Referências BibliogrÁficas}

ANTUNES JR., José Antônio Valle (coord.). Competitividade e tecnologia: análise e perspectivas da indústria moveleira do Rio Grande do Sul. Secretaria de Ciência e Tecnologial Banco de Desenvolvimento do Estado do Rio Grande do Sul S/A - BADESUL, IDERGS/ Sistema FIERGS, 1991.

BACIC, M. J. e SOUZA, M. C. A. F. Pensando Políticas Públicas para as pequenas e médias empresas: importância das formas de inserção e as condições de apropriação dos benefícios. In: REE. Brasília, 1998. p.03-16.

BARDI, P. M. Excursão ao território do Design. São Paulo: Banco Sudameris Brasil, 1986.

BASTOS, Cleverson e KELLER, Vicente. Aprendendo a aprender introdução à metodologia científica. Petrópolis: Editora Vozes, 1996.

BAXTER, Mike. Projeto de produto. São Paulo: Editora Edgard Blücher Ltda., 1995.

BONSIEPE, Gui. A "tecnologia" da tecnologia. São Paulo: Editora Edgard Blücher Ltda. 1983.

. Design: do material ao digital. Florianópolis: FIESC/ IEL, 1997.

BONSIEPE, Gui, WALKER, Rodrigo. Um experimento em projeto de produto/Desenho Industrial. Brasília: $C N P q /$ Coordenação Editorial, 1983.

CERQUEIRA, Nelson. O Design e a competitividade empresarial. Guia para orientação. Salvador: Publicação no Brasil Instituto Euvaldo Lodi/Sudene/Bahia Design, 1994.

CORIAT, Benjamin. Ciência, técnica y capital. Madrid: $H$. Blume Ediciones, 1976.

COUTINHO, Luciano (coord.). Design na indústria brasileira de móveis. Campinas: SEBRAE/FINEP/ABIMÓVEL/ FECAMP/UNICAMP/IE/NEIT, 1999.
COUTINHO, Luciano e FERRAZ, João Carlos (coords). Estudos da competitividade da indústria brasileira. Campinas: UNICAMP / Papirus, 1994.

DE MORAES. Limites do Design. São Paulo: Editora Studio Nobel, 1997.

DOBLIN GROUP RESEARCH, Genericdesign estrategies An executive summary (paper). Chicago: set., 1993.

ESTRATÉGIAS SETORIAIS - Setor: Moveleiro (Móveis e Madeiras) - Documento de Trabalho. Brasília: Departamento da Indústria e do Comércio, nov., 1990.

FERRAZ, João Carlos; HAGUENAUER, Lia e KUPFER, David. Made in Brazil. Desafios competitivos para a indústria. Rio de janeiro: Editora Campus Ltda., 1997.

FERREIRA, Aurélio Buarque de Holanda. Novo dicionário da língua portuguesa. 2ed. Rio de Janeiro: Editora Nova Fronteira S. A., 1986.

FERREIRA, Manoel P. Introdução ao Desenho Industrial. Rio de Janeiro: Confederação Nacional da Indústria Departamento de Assistência a Média e Pequena Indústria, 1980.

FERREIRA, Maria Cristina (org.). Normas e orientações para apresentação de trabalhos acadêmicos. Curitiba: Faculdade de Administração e Economia - FAE, 1995.

FONTOURA, Ivens. Móvel, o melhor amigo do homem. Revista do SIMOV, Curitiba, ano 01, n.01, p.4, jun./jul. 2000.

GALEANO, Eduardo. As veias abertas da América Latina. Rio de Janeiro: Editora Paz e Terra, 1996.

GAPSKI, Maria Leni et al. Contextualização da arte, da técnica e da tecnologia no Design Industrial: um estudo de caso na empresa Electrolux. Curitiba, 1997. 86p. Trabalho de disciplinas de Mestrado, Centro Federal de Educação Tecnológica do Paraná.

GUIMARÃES, Ana Lúcia Santos Verdasca. Diagnóstico Industrial: Desenvolvimento de Produtos. Curitiba, 1999. 130 p., Dissertação (Mestrado em Inovação Tecnológica) Programa Pós-graduação em Educação, CEFET-PR.

HAWKEN, Paul; LOVINS, Amory e LOVINS, L. Hunter. Capitalismo Natural. Criando a próxima Revolução Industrial. São Paulo: Cultrix, 1999.

HESKETT, John. Integrating Design into industry. Design Processes Newsletter. In: MAGALHÃES, Cláudio Freitas de. Design estratégico: integração e ação do design industrial dentro das empresas. Rio de Janeiro: SENAI/DN, SENAI/ CETIQT, CNPq, IBICT, TIB, 1997.p. 17-17. 
INDICADORES DE COMPETITIVIDADE PARA MICRO E PEQUENAS EMPRESAS INDUSTRIAIS NO BRASIL. Brasília: Edição SEBRAE/UFRJ-IEI, 1993.

JACOBS, Dirk. O valor de produtos. Fórum ICSID Design no Mercosul. Anais do 1 Fórum ICSIDDesign no Mercosul. Florianópolis: SENAI/LBDI, 1995.

KOTLER, Philip. Administração de Marketing. São Paulo: Editora Atlas S. A., 1994.

LASTRES, H. M. M. et al. Design para a competitividade: recomendaçôes para a política industrial no Brasil. Relatório síntese. Rio de Janeiro: Confederação Nacional da Indústria-CNI/DAMP/Núcleo de Design, 1996.

MAGALHÃES, Cláudio Freitas de. Design estratégico: integração e ação do design industrial dentro das empresas. Rio de Janeiro: SENAI/DN, SENAI/CETIQT, CNPq, IBICT, TIB, 1997.

Design Estratégico: integração e ação do design industrial. Estudos em Design, Rio de Janeiro, v.3, n.1, p. 16, jul. 1995.

MANU, Alexander. O design como integração. Fórum ICSID Design no Mercosul. Anais do 1 Fórum ICSID Design no Mercosul. Florianópolis: SENAI/LBDI, 1995.

MANZINI, Ezio. The material of invention, material and design. Milão: Arcadia, 1986.

\section{MINISTÉRIO DA INDÚSTRIA, DO COMÉRCIO E DO} TURISMO, POLÍTICA INDUSTRIAL E DE COMÉRCIO EXTERIOR, Programa brasileiro doDesign. Brasília: CNI, SEBRAE, 1997.

MOTOYAMA, Shozo (org.). Tecnologia e industrialização no Brasil. São Paulo: UNESP / CEETEPS, 1994.

NAHUZ, Márcio Augusto R. Uso nobre para madeira comum. Anais do Seminário Materiais \& Design, 1997. São Carlos: IBICT/CNPq/Federação e Centro das Indústrias do Estado de São Paulo/Universidade Federal de São Carlos, 1998.

PALADINI, Edson Pacheco. Qualidade total na prática. 2.ed. São Paulo: Editora Atlas S. A., 1997.

PASSOS, C. A K. Novos Modelos de Gestão e as Informações. In LASTRES, H. M. M., ALBAGLI, S., Informação e Globalização na Era do Conhecimento. Rio de Janeiro. Campus, 1999, p. 58-83

POPCORN, Faith. O relatório Popcorn. Rio de Janeiro: Editora Campus Ltda., 1997.

PORTER, Michael. Estratégia competitiva: técnicas para a análise da indústria e da concorrência. Rio de Janeiro:
Editora Campus Ltda., 1986.

. Vantagem competitiva. Rio de Janeiro: Editora

Campus Ltda., 1992.

PROGRAMA DE APOIO TECNOLÓGICO ÀS MICROE PEQUENAS EMPRESAS - PATME. Programa de extensão tecnológica para a área de Design moveleiro. Relatório de trabalho. Curitiba: Merege Design. Consultoria em Design de produto, 1996.

PROGRAMA SÃO PAULO DESIGN - Diagnósticos setoriais. São Paulo: Governo do Estado de São Paulo/Programa Brasileiro de Design/Instituto de Pesquisas Tecnológicas/ FIESP-CIESP, 1997, CD ROM.

PUERTO, Henry Benavides. Design e inovação tecnológica. Coletânea de idéias para construir um discurso. Salvador: IEL/Programa Bahia Design, 1996.

Relação e ingerência do desenho industrial no processo de inovação tecnológica no contexto brasileiro. O papel dos designers industriais nos institutos de pesquisa aplicada. São Paulo: 1997, 197p. Dissertação (Mestrado em Estruturas Ambientais Urbanas) - Curso de Pós-graduação da Faculdade de Arquitetura e Urbanismo-FAU, Universidade de São Paulo - USP.

RANGEL, Armênio de Souza (elaboração). Estudo da competitividade da indústria brasileira Competitividade da indústria de móveis de madeira (mimeo). Campinas: IE/UNICAMP/-IEI/UFRJ-FDCFUNCEX, 1993.

RIBEIRO, Darcy. O povo brasileiro. São Paulo: Editora Companhia das Letras, 1995.

SCHULMANN, Denis. O Desenho Industrial. Campinas: Papirus, 1994.

SEIBEL, Silene (coord). Made in Brazil. Benchmarking da prática e performance da produção Industrial. Florianópolis: IEL/FIESC, 1998.

SLACK, Nigel et al. Administração da produção. São Paulo: Editora Atlas S. A., 1997.

SILVA, Edna da e MENEZES, Estera Muszkat. Metodologia da pesquisa e elaboração de dissertação (mimeo). Florianópolis: Universidade Federal e Santa Catarina / Programa de Pós-graduação em Engenharia de Produção / Laboratório de Ensino a Distância, 2000.

SUNKEL, Osvaldo e PAZ, Pedro. El subdesarrollo y la teoria del desarollo. México: Siglo XXI Editores, 1970.

SUZIGAN, Wilson. Indústria brasileira: origem e desenvolvimento. São Paulo: Editora Brasiliense, 1986. 
TEIXEIRA, Joselena de Almeida. Design \& Materiais. Curitiba: Editora CEFET-PR, 1999.

ZACCAI, Gianfranco. O desenho industrial como uma ferramenta estratégica de desenvolvimento econômico. Fórum ICSID Design no Mercosul. Anais do 1 Fórum ICSIDDesign no Mercosul. Florianópolis: SENAI/LBDI, 1995. 